This is an Accepted Manuscript of a chapter in The Palgrave Handbook of Age Diversity and Work, published by Palgrave Macmillan in 2017. Article DOI https://doi.org/10.1057/978-1-13746781-2_11.

UNDERSTANDING RETIREMENT PROCESSES: THE ROLE OF LIFE HISTORIES

\title{
Marleen Damman
}

Netherlands Interdisciplinary Demographic Institute (NIDI-KNAW) / University of Groningen, The Netherlands

Chapter for Handbook on "Age Diversity and Work"

August 18, 2015 


\section{Introduction}

In most developed countries populations are aging rapidly due to long-term declines of fertility and increasing longevity (Wheaton and Crimmins 2012). These demographic developments have important implications for public finances, pension systems, labor markets, and organizations. Extending the working lives of older individuals is often perceived as a key policy response to population aging (OECD 2006), putting the issue of retirement high on the policy agenda as well as the scientific agenda. In this respect, insights are needed into factors that inhibit or rather stimulate the continuation of work careers, and keep workers engaged and motivated during late careers. Moreover, in the coming decades numerous older workers will transition into retirement, which raises questions about how individuals experience their retirement and about factors that predict successful adjustment to retirement.

Research on retirement is a broad and interdisciplinary field of study. Demographers, economists, gerontologists, psychologists, and sociologists are among the scholars interested in questions related to retirement. There is no general agreement on the definition and measurement of retirement: it can refer to (partially) leaving the labor force during late careers, receipt of pension income, self-assessment by respondents, or combinations of these and other indicators (Denton and Spencer 2009, Ekerdt 2010, Beehr and Bowling 2012). However, most researchers would agree that retirement "relates to withdrawal from the paid labour force", as Denton and Spencer $(2009$, p.64) point out in their review of retirement concepts and measurements.

Whereas some studies move beyond the disciplinary borders, the aspects of retirement transitions studied and the types of predictors that are taken into account seem to vary between disciplines (Henkens 1998). 
Demographic, economic, and sociological studies generally focus on explaining differences in retirement-related behaviors and states, such as labor participation during late careers, actual retirement timing, and differences in retirement savings or income. Studies on more subjective facets that precede or follow upon the act of retirement are often found in the literatures of organizational psychology and social-gerontology. These studies largely focus on intentions and attitudes of individuals, such as their intentions regarding late-career work or retirement timing, and adjustment to retirement. In the scientific literature, retirement is often referred to as being a process, rather than a discrete one-time event. What is actually meant by the term 'process', however, varies considerably between studies and disciplines (see Text Box 1). The term has been used to indicate that retirement consists of several broad phases (e.g., preretirement planning, retirement decision-making, postretirement adjustment), but also to refer to more specific behavioral or attitudinal dynamics within or across these phases. In most empirical studies, however, researchers solely focus on one phase or aspect of the retirement transition, "cognizant that they are studying just one piece of the larger retirement puzzle" (Shultz and Wang 2011, p.172).

\section{[TEXT BOX 1 ABOUT HERE]}

For explaining differences between individuals in terms of their retirement intentions, acts, and attitudes, a large variety of factors has been studied. In a recent review of the multidisciplinary retirement literature, Wang and Shultz (2010) have grouped the empirically studied predictors of retirement in four broad categories. Besides macro socio-economic factors (e.g., social security system, economic conditions), three groups of meso and micro level predictors of retirement are distinguished: individual attributes (e.g., age, health, financial resources), job and organizational factors (e.g., job characteristics, job attitudes), and family 
factors (e.g., marital status, dependent children, partner support). Also in terms of the types of predictors studied, disciplines seem to vary in their focus. For example, where sociologists are mostly interested in the role of socio-economic and socio-demographic differences (e.g., type of work) for explaining variation in retirement transitions, psychologists often focus on more subjective factors (e.g., perceived work challenge).

To acquire insights into variation in retirement-related decisions and experiences, research in these various disciplines has to a large extent focused on explanatory factors that are relatively close in time to the retirement outcomes studied, such as the health, wealth, work, and family situation of older individuals. These precursors received attention in various recent extensive reviews of the literature on employee retirement (e.g., Schalk et al. 2010, Wang and Shultz 2010) and adjustment to retirement (e.g., Wang et al. 2011, Van Solinge 2012). In line with the popularity of the "life course perspective" for understanding outcomes in the field of social gerontology however, studies have increasingly started to pay attention to the role of experiences earlier in the life course for understanding retirement transitions. The role of these earlier life experiences for explaining retirement-related decisions and experiences will be the main focus of the current chapter.

\section{Relevance of focusing on life histories and retirement}

The life course perspective proposes - among other things - that specific life phases cannot be understood thoroughly without information on the prior life course (Elder 1994). Individual development is assumed to be lifelong: the lived past will set the stage for later decisions and experiences (Settersten 2003). Studying the role of earlier life experiences has been fruitful for explaining various outcomes among older individuals. For example, for explaining differences in 
terms of the financial situation of older individuals (Fokkema and Van Solinge 2000, Fasang et al. 2012), health (Wahrendorf et al. 2013, Hank 2010), and well-being (Peters and Liefbroer 1997) information about life histories proved to be informative. The scientific literature regarding the role of earlier life experiences for explaining variation in retirement transitions is still rather fragmented, but has been growing rapidly the last decade. This makes it relevant to review the theoretical approaches that have been taken, to describe the empirical findings, and to discuss potential directions for future research.

Improving our understanding of the relationships between experiences earlier in life and retirement is not only important from a scientific perspective, but is relevant from a societal perspective as well. Firstly, in the policy-oriented literature it is expected that experiences earlier in life are of importance for the retirement transitions of older workers. For example, mid-career measures directed at occupational health and safety, and opportunities for learning new skills or improving skills are anticipated to positively influence labor market participation as individuals age (OECD 2006). In this respect, the OECD (2006) mentions that "some policy interventions to encourage later retirement should, in fact, focus on workers at younger ages" (p.135). Studying the life course embeddedness of retirement may therefore offer starting points for mid-life interventions or policy design, by testing the underlying assumption that earlier life experiences continue to affect the lives of individuals even in their later years.

Secondly, improving our understanding of the relationships between earlier life experiences and retirement is relevant in light of the changes in life courses that have been observed during the twentieth century. The 'standard life course' - where paid work was central in the lives of men, housework and care tasks were central in the lives of women, and couples stayed together until death did them part - seems to have become less evident, as has lifetime 
employment at a single employer. What consequences will these changes in individual life courses have for the retirement-related decisions and experiences of older individuals? When achieving a better understanding of how retirement transitions of current retirees are related to their experiences earlier in life, we may be better able to predict how changing life course experiences might shape the retirement experiences of future retirees (cf., Börsch-Supan et al. 2013).

\section{This chapter}

The current chapter will review the scientific literature on the relationships between earlier life experiences and retirement of older individuals. The next paragraph will describe important changes in individual life courses during the last decades, specifically focusing on experiences in the spheres of work and family. Thereafter, attention will be paid to the theoretical starting points in the research on life histories and retirement, followed by an overview of empirical findings. The last paragraph will conclude and will discuss the findings of the review. Generally the aims of this chapter are (1) to provide an overview of the current state of scholarly discussions on life histories and retirement, (2) to formulate recommendations for future research, and (3) to discuss implications for organizational and public policy.

\section{Changing life courses}

The present older workers and recent retirees in developed societies have grown older in times where major societal changes, as well as changes in individual life courses have taken place. Various structural changes (e.g., the shift from an industrial to a post-industrial or service economy, globalization) and cultural developments (e.g., secularization, the emancipation of 
women, and individualization) form the context in which individual life courses have become increasingly diverse. Without aiming to provide a complete overview of the life course changes in developed societies during the last decades, this paragraph will shortly highlight some important developments in terms of individual life courses during the twentieth century. First, it will describe changing experiences in the sphere of work, such as developments in labor force participation, and job mobility over time. Thereafter, changing experiences in the family sphere will be discussed, such as developments in terms of childbearing, marriage, and divorce.

\section{Changing working lives}

One of the central developments in terms of work careers in OECD countries in the period since the second World War is the continued progress made by women in educational achievements and labor market participation (OECD 2002). The gender gap in employment has become smaller due to employment gains for women and employment reductions for men, even though the timing and pace of these developments differ considerably between countries. Whereas in the Nordic European countries, the increase in female labor force participation had already been observed in the 1960s and 1970s, in countries like the Netherlands, Ireland, and Portugal this trend was more pronounced in the 1980s and 1990s. Between 1980 and 2000, for example, the gender gap in employment rates of men and women narrowed by more than 20 percentage points in these latter three countries (OECD 2002). In these countries, clear inter-generational differences in employment patterns have been found, where successive birth cohorts of women show a considerable increase in terms of (re)entry in the labor market. In the Netherlands, for example, a study on changing life course experiences across birth cohorts has shown that about $60 \%$ of the women born between 1961 and 1970 has a fulltime or part-time job at age 30, 
compared with 36\% of the women born between 1941 and 1950 (Liefbroer and Dykstra 2000). In several southern European countries, such as Italy, Greece, and Spain, the gender employment gap has narrowed, but was still considerable at the beginning of this century (OECD 2002). Figure 1 shows the labor force participation rates for men and women for a selection of OECD countries in 2013, sorted by the labor force participation rates of women. Even though labor force participation of women increased considerably during the last decennia, it should be noted that part-time work is still more common among women than among men across OECD countries (OECD 2014a).

[FIGURE 1 ABOUT HERE]

The nature of work and careers seems to have changed over time as well, although also here considerable differences can be observed between countries. A widespread assumption in the employment literature is that "globalization breeds widespread employment flexibility that translates into unstable, fragmented and precarious employment careers" (Mills and Blossfeld 2006, p.465/466), which has been referred to as the 'patchwork career thesis'. However, results of a comparative study across 12 different OECD countries to test this thesis among mid-career men - a group of workers who are already established in the labor market - show a mixed picture. The extent to which the level of employment flexibility has changed over time largely seems to be dependent upon the institutional country context. Whereas in countries such as Italy, Sweden, and Germany no evidence of the emergence of patchwork careers could be found among mid-career men, in other countries such as the Netherlands and the United States, midcareer men increasingly experienced patchwork career patterns (Blossfeld et al. 2006). By analyzing data of different retrospective life history surveys in the Netherlands, Luijkx, Kalmijn, and Muffels (2006) have for example shown that male careers have become more non-standard 
and flexible over time. A steady increase in career mobility (i.e., downward, upward, and lateral mobility) is observed, particularly in the last decades of the twentieth century (Luijkx et al. 2006). For the United States a meta-analysis of studies on employment mobility by Mills, Johnston, and DiPrete (2006) shows that overall levels of mobility in the United States are high and have increased since the 1970s. Even groups that were traditionally perceived as more 'protected' in the labor market, such as male white-collar workers and more experienced workers, were increasingly exposed to job loss (Mills et al. 2006).

\section{Changing family lives}

Not only in the sphere of paid work, but also in the family domain, important changes have been observed during the last decades. The average number of children per woman (i.e., the completed fertility rate) declined across cohorts in almost all countries in the OECD Family Database. Women born in 1950 had on average more children at the end of their childbearing years as compared with women born in 1965. Figure 2 shows the completed fertility rates per birth cohort, for a selected group of countries for which the data are available. Related to these numbers on completed fertility is the share of women remaining childless. The share of definitive childless women per cohort increased noticeably for the cohorts born between 1950 and 1965. In the Netherlands, for example, the percentage of definitive childlessness increased from $14.6 \%$ among women born in 1950 to $18.3 \%$ of women born in 1965 . Moreover, changes in terms of the timing of childbearing have been observed. In the vast majority of OECD countries, the transition into motherhood has been postponed since the 1970s. Whereas in most countries (e.g., France, the Netherlands, Denmark) the average age of women at birth of a first child showed the steepest increase between 1970 and the mid-1990s, for other countries (e.g., Czech 
Republic, Hungary, Portugal) the increase was more pronounced between the mid-1990s and 2009. The average age at birth of a first child in OECD countries was 27.8 years in 2011 (OECD 2014c).

\section{[FIGURE 2 ABOUT HERE]}

Concurrently with changes in childbearing patterns, important changes in terms of the formation and dissolution of partner relationships have also taken place. Partner relationships seem to have become more diverse. Increasingly individuals cohabit before they get married, postpone marriage, or do not marry at all. Cross-national analyses by Hiekel (2014) based on data of the Generations and Gender Surveys ${ }^{1}$ have, for instance, shown that the share of first unions that started as unmarried cohabitation increased considerably for subsequent birth cohorts in a broad range of European countries. Even though the starting values as well as the magnitude of the growth differ between countries, generally there seems to be a trend towards unmarried cohabitation as the first co-residential union type formed. The permanency of cohabitation (i.e., the median duration) generally increased across cohorts as well, which mainly seems to be driven by the increasing postponement of the transition into marriage (Hiekel 2014, p.14-19). Data from the OECD Family Database (OECD 2014c) show the decreasing popularity of marriage over time. Since the 1970s crude marriage rates ${ }^{2}$ have dropped for almost all OECD countries. Moreover, marriages have become less stable. Figure 3 presents the increase in crude divorce rates between 1970 and 2008 for a selection of countries, based on data from the OECD

\footnotetext{
${ }^{1}$ The GGP (i.e., Generations \& Gender Programme) is a large cross-national longitudinal survey of 18-79 year olds, in which a broad array of topics including partnerships, fertility, economic activities, and care duties are included (see: http://www.ggp-i.org).

${ }^{2}$ In the OECD Family Database the crude marriage rate is defined as "the number of marriages formed each year as a ratio to 1000 people. This measure disregards other formal cohabitation contracts and informal partnerships".
} 
Family Database. It clearly shows that divorce rates increased in most of the OECD countries since the 1970 s.

\section{[FIGURE 3 ABOUT HERE]}

The changes in individual life courses that have been observed during the last decades will be reflected in the lives of many individuals that are approaching their late careers. Older workers are an increasingly heterogeneous group in terms of their work and family histories, and this variation in earlier life experiences is often assumed to be of importance for understanding differences in their retirement-related decisions and experiences: "retirement decision processes evolve from a variety of contextual influences and lifelong experiences in divergent realms" (Szinovacz 2003, p.29). Especially for studying the attitudes and behaviors of older individuals it might be important to take variation in terms of earlier life experiences into account, given that they draw from a relatively great "pool of experiences" (Pienta 1999, p.70). The next paragraph will elaborate on the theoretical perspectives that have been used in the existing literature to link life histories to retirement transitions.

\section{Life histories and retirement: theoretical starting points}

The life course perspective is the central theoretical starting point for research on the relationships between earlier life experiences and retirement. Key organizing concepts of the life course are transitions and trajectories (Elder and Johnson 2003). Transitions - gradual changes that are generally tied to entering or exiting roles - are assumed to be embedded within multiple interdependent trajectories (for example, work, family, and health trajectories). This suggests that single transitions, such as the transition from work into retirement, cannot be understood in isolation from the experiences and contexts that surround it (Settersten 2003). According to the 
life course perspective earlier experiences in different life spheres, but also the lives of other individuals ('linked lives'), socially shared ideas regarding the appropriate timing and sequencing of life events, and historical time and place are important contexts shaping the lives of individuals (Dykstra et al. 2007). In this section the theoretical mechanisms that have been distinguished in the literature to link earlier life experiences to retirement processes will be described, followed by a discussion on theoretical ideas about retirement decision-making.

\section{Linking mechanisms}

Even though the life course perspective proposes that earlier life experiences are of importance for understanding later outcomes, it does not provide clear-cut theoretical ideas about mechanisms linking these factors to specific outcomes. In the sociological retirement literature, however, some ideas have been presented about these linking mechanisms.

Generally, earlier life experiences are expected to affect retirement via their influence on the individual opportunity structure in later years. In this respect, pensions and other types of individual financial resources are the most obvious mechanism for linking earlier events to later outcomes (Henretta 2003), given that these resources are dependent upon earnings over time. Not only experiences in the work sphere, but also family histories have been found to be related to pension coverage (Yabiku 2000, Price and Ginn 2003), and preretirement wealth (Wilmoth and Koso 2002, Holden and Kuo 1996). Given that the impact of life experiences might accumulate over time - either positively (cumulative advantages) or negatively (cumulative disadvantages) - financial inequality is particularly high among older individuals (O'Rand 1996), which might offer an important explanation of variation in retirement behaviors and experiences. Those individuals having a more beneficial financial situation might be able to retire relatively 
early. In studies on life histories and retirement, the financial argument is the most central argument that has been used to theoretically link earlier experiences to later outcomes: Earlier life experiences will affect preretirement financial opportunities and constraints and consequently retirement decisions (e.g., Hank 2004, Hayward et al. 1998, Szinovacz and DeViney 2000, Damman et al. 2011).

Earlier life experiences might, however, not only shape retirement transitions by affecting the financial situation in late life, but also by affecting other aspects of the late-career opportunity structure, such as the older individual's health condition, work context, or family situation. For example, individuals who experienced health problems in mid-life might be more likely to experience health problems during late careers as well - given that health problems seem to have long-term consequences (Blackwell et al. 2001) - and these preretirement health problems might increase the likelihood of early retirement. Those who invested more in education might be more likely to have a job characterized by a high level and broad scope of cognitive challenge during their late career (Hyllegard and Lavin 1992), which might make continued work more attractive. Older workers who made the transition into parenthood relatively late might be more likely to have dependent children still living at home, which could make individuals feel less entitled to adopt the retiree role (Choi 2002). Via this line of reasoning, therefore, earlier life experiences might also be associated with retirement because of their consequences for the non-financial aspects of the late-career opportunity structure.

Yet another mechanism that has been proposed in the literature to link earlier experiences to retirement is an individual's orientation towards work and family roles across the life course. This mechanism does not specifically refer to the late-career opportunity structure as a mediating factor between earlier experiences and later outcomes, but rather points at underlying 
orientations that are assumed to shape life experiences both earlier and later in life. The general assumption is that the lives of individuals show a great deal of continuity between earlier and later points in time, due to these underlying orientations towards work careers and family life. For example, more work-oriented women are expected to have stronger ties to the labor market both earlier and later in their life course, resulting in the expectation that "delaying childbearing, forgoing childbearing, and having smaller families will foster stronger labor force attachment throughout the life course-including retirement years" (Pienta 1999, p.72). Hank (2004) also refers to women's career orientations to interpret his study finding that women who made the transition into motherhood relatively late or mothers who remained employed during the early childrearing years were more likely to delay retirement. Postponing childbearing and postponing retirement are both expected to be driven by a relatively strong work career orientation. Figure 4 provides a schematic overview of the three central hypothesized mechanisms linking earlier life experiences to retirement processes.

\section{[FIGURE 4 ABOUT HERE]}

\section{Retirement decision-making}

The ways in which late-career opportunity structures and orientations towards work and family are translated into retirement transitions remain unspecified in the life course perspective. The life course notion of 'agency within structure' suggests that individuals actively create their life course within the opportunities and constraints of their social worlds (Settersten 2003), but does not specify how individuals will make their decisions. As Mayer (2009) has noted in a recent review: "life course sociology lacks a coherent body of theory" (p.423). Studies on retirement therefore often - implicitly or explicitly - incorporate a resource perspective and rational choice framework to formulate hypotheses. The term rational choice refers to a family of behavioral 
theories in the social sciences "that proceed from the twin assumptions that human beings pursue goals and that, being confronted with opportunities and limitations for reaching their goals, they do so in a more or less intelligent way" (Lindenberg 2006, p.548). From a rational choice perspective, individuals making work and retirement decisions during late careers are generally assumed to weigh the pros and cons, the costs and benefits, or the push and pull factors of their current life situation and their expected future situation in retirement (Feldman and Beehr 2011, Van Solinge and Henkens 2014). If the perceived benefits of retirement exceed the perceived benefits of working, individuals are expected to decide to make the transition into retirement. The factors that are assumed to play a role in these considerations are not restricted to the individual's financial resources, but can for instance also include the individual's health, work situation, social resources, and value orientations.

When systematically applying the theoretical reasoning that earlier life experiences might be associated with retirement via the financial late-career opportunity structure, via the nonfinancial late-career opportunity structure, or via underlying orientations, it becomes clear that opposing forces might be at work between specific earlier life experiences and retirement. For example, the experience of upward mobility during mid-life might positively affect the financial opportunity structure in preretirement years. Given this more beneficial financial situation, retirement (versus continued work) might become a viable and attractive option at a younger age. Therefore, upwardly mobile individuals can be hypothesized to retire relatively early. However, when also taking the potential consequences of earlier life experiences for the non-financial aspects of the late-career opportunity structure into account, an opposite prediction can be made. In the case of upward mobility it can be expected, for instance, that upward career mobility improves working conditions (e.g., more self-direction), which might make continued work 
relatively attractive. Consequently, when reasoning via the work opportunity structure, upwardly mobile individuals can be hypothesized to retire relatively late. This complexity of potentially offsetting ways in which earlier life experiences could be related to retirement transitions has only recently been made more explicit in the retirement literature (e.g., Damman et al. 2011, Raymo et al. 2011, Hank 2004).

One difficulty when studying the relationships between earlier life experiences and retirement is that the theoretical utility of the conceptualization of retirement as a rational decision-making process will be dependent upon the extent to which retirement transitions are the result of personal choice (Wang and Shultz 2010). Research has shown that many retirement transitions (around 25-30 percent) are perceived as forced or involuntary (Szinovacz and Davey 2005, Van Solinge and Henkens 2007). Therefore, earlier life experiences might be stronger predictors of some aspects of the retirement process than of other aspects. For example, earlier life experiences might be stronger precursors of subjective processes that precede the actual act of retirement such as retirement timing intentions, than of actual retirement behavior (Beehr 1986). Whereas retirement intentions might reflect the outcome of the individual considerations of the pros and cons associated with continued work versus retirement at a given age, the actual age of retirement might for a considerable share of individuals be determined by external forces that restrict the leeway that individuals have to make their own decisions. As Szinovacz (2003) argues: "It is only when choice exists that cost-benefit considerations enter retirement decisions" (p.21). This suggests that to achieve an in depth picture of the life course embeddedness of retirement, it would be informative to simultaneously examine several aspects of the process of retirement - such as retirement planning, retirement preferences and intentions, actual retirement timing, and postretirement adjustment - in relation with experiences earlier in life. 


\section{Life histories and retirement: empirical findings}

Empirical research on retirement has predominantly been focused on proximal precursors of retirement, that is, precursors that are close in time to the retirement transition (Settersten 2003). These proximal characteristics might imply earlier life events (Szinovacz 2003, Henretta 2003), but rarely convey detailed information about specific earlier life course experiences. Some studies have looked a bit further back in time by supplementing proximal factors with single indicators of career or marital continuity, such as job tenure (Brown and Warner 2008, Hayward et al. 1989, Szinovacz and Davey 2005, Wong and Hardy 2009, Jones and McIntosh 2010), years in the labor force (Mutchler et al. 1997, Van Solinge and Henkens 2005), number of times laid off (Flippen and Tienda 2000), or the length of one's current marriage (Ho and Raymo 2009, Pienta 2003). Even though these studies assume that it is important to take information about the prior life course into account for understanding retirement transitions, they do not provide detailed insights regarding the extent to which and how specific earlier life experiences affect retirement decisions and experiences. However, the number of studies that more systematically examine the relationships between earlier life experiences and retirement seems to have grown rapidly during the last decade. In the following paragraph empirical findings regarding work histories and retirement timing will be described, followed by a paragraph on family histories and retirement timing. Thereafter, attention will be paid to empirical research on more subjective aspects of the retirement process in relation with life histories, which is an area of research that has received only limited empirical attention thus far.

\section{Work histories and retirement timing}


In the literature focusing on retirement-related behavior - mostly conducted by sociologists - the role that earlier life experiences in different life spheres play for understanding retirement transitions has nowadays received considerable attention. With respect to work careers these studies have, for instance, investigated the role of diverse career pathways (Han and Moen 1999, Pienta et al. 1994, Kovalenko and Mortelmans 2013), exposure to certain types of jobs over the career (Elder and Pavalko 1993, Hayward et al. 1998, Raymo et al. 2011), and diverse indicators of employment continuity and career mobility (Damman et al. 2011, Finch 2014, Raymo et al. 2009, Raymo et al. 2010, Singh and Verma 2003, Henretta et al. 1993) for explaining late-career labor market behaviors. Even though insights are still rather fragmented - given that studied earlier life experiences and country contexts differ much between studies - a general sketch of some findings could be provided. With respect to labor force participation, research findings have shown that women who have worked continuously throughout the life course are more likely to work during later life (Pienta et al. 1994), and to work beyond pension age (Finch 2014), which seems to be in line with the notion of continuity between earlier and later points in time in terms of labor participation. For men, the findings are mixed, with some studies showing that a history of unemployment and labor force exits places male workers at a higher risk of retirement (Hayward et al. 1998), and other studies showing that discontinuous employment and involuntary job loss in mid-life result in lower odds of retirement (Raymo et al. 2009, Raymo et al. 2011).

With respect to job mobility, the research results generally seem to suggest that those individuals who followed a traditional stable career path retire relatively early. Han and Moen (1999) showed that those retirees who have had an 'orderly career path' - characterized by ladder climbing within the same firm - retired the earliest, and among those men more so than 
women. Similarly, by analyzing more recent data of the SHARELIFE ${ }^{3}$ survey, Kovalenko and Mortelmans (2013) have shown that individuals following a so-called 'stepping stone' career trajectory - characterized by a main job of a prolonged duration that is held until retirement retire earlier than those individuals who had a 'hypertransitional' career trajectory. Other studies suggest as well that mobility is associated with later retirement among men, by showing that mid-life employer changes are associated with weaker intentions to retire early (Damman et al. 2011), and that a shorter job tenure decreases retirement risks (Hayward et al. 1998).

\section{Family histories and retirement timing}

The role of earlier experiences in the family sphere - such as fertility and marital histories - for understanding retirement-related behaviors has been examined in various empirical studies. With respect to fertility histories, the relationships with late-career labor market behaviors were traditionally especially examined among women. However, increasingly these relationships also receive attention in studies including men (e.g., Damman et al. 2011, Hank and Korbmacher 2013). Research findings regarding fertility histories and retirement are rather mixed though, even when focusing on women. Whereas some studies have shown that the number of children is not clearly associated with labor force exit among women (Pienta 1999, Finch 2014), other studies have shown that having (more) children is associated with later retirement (Chung 2010, Hank 2004, O'Rand and Henretta 1982). A recent study by Hank and Korbmacher (2013) based on the SHARELIFE data has revealed that the impact of the number of children on women's retirement timing differs across birth cohorts. Among women born before 1940 having more

\footnotetext{
${ }^{3}$ The SHARE survey (i.e., the Survey of Health, Ageing and Retirement in Europe) is a large cross-national panel survey on health, socioeconomic status, and social networks of Europeans age 50 and over, which started in 2004. In the third wave (2008-2009), retrospective life history data on the topics of children, partners, accommodations, employment, health, childhood circumstances, finances, and general life events were collected in the so-called SHARELIFE survey (see: www.share-project.org).
} 
children is related to lower odds of entering retirement, while among women born after 1940 having more children is related to a higher odds of retirement, which might be due to greater economic and institutional opportunities for early exit among these younger cohorts. Also with respect to the timing of having a first child, conclusions vary across studies. Some authors conclude that the timing of first birth does not seem to matter much for explaining late-career labor force exit (Finch 2014, Hank and Korbmacher 2013), others conclude that having a first child relatively early is related to a lower likelihood of self-defined retirement and labor force exit (Chung 2010), and yet others find that a relatively late transition into motherhood is associated with rejection of the retiree identity (Szinovacz and DeViney 1999), and later labor force exit (Hank 2004, Pienta 1999). Damman, Henkens, and Kalmijn (2014) showed that women who transitioned into motherhood relatively late and still have children living at home during preretirement years intend to retire relatively late, but do not actually retire later. Overall, it should be noted that the way in which fertility histories are measured and included in the statistical models (e.g., the age boundaries for distinguishing 'early' and 'late' first births and the reference groups used) differs greatly between studies. Moreover, studies vary a lot in terms of other variables that are taken into account in the models, operationalization of dependent variables, country contexts, and birth cohorts studied, which might all account for differences in findings across studies.

With respect to marital histories, the research findings seem to be more unequivocal, especially when focusing on women. Generally currently divorced women have been found to be more likely than married women to be engaged in paid work during late careers (Choi 2002, Pienta 1999, Pienta et al. 1994) and seem to retire later (e.g., Brown and Warner 2008, Raymo et al. 2011), suggesting that the experience of a divorce affects retirement timing. By focusing on 
current marital status, however, the long-lasting impact of divorce experiences earlier in life and the effect of repartnering cannot be captured. Therefore, recent studies have examined the impact of marital histories in more detail. Findings from studies in the United Kingdom and the Netherlands suggest that especially women who have ever been divorced and did not repartner are most likely to extend their working lives (Damman et al. 2014, Finch 2014). Women who have ever been divorced and repartnered, were found not to differ from continuously married women in terms of their retirement intentions and behavior (Damman et al. 2014, Szinovacz and DeViney 2000). This suggests that repartnering might at least partly compensate the negative consequences of a divorce. Among men who live with a partner, late-career labor market behaviors also do not seem to differ much between those who did and those who did not experience a divorce earlier in life (Finch 2014, Szinovacz and DeViney 2000). With respect to the timing of a divorce, research suggests that especially experiencing a divorce later in mid-life is associated with weaker intentions to retire early among both men and women (Damman et al. 2011, Damman et al. 2014). Also here it should be noted that the impact of divorce experiences might differ between country-contexts. Fasang (2008) showed in her comparative study on the timing of pension entrance in Germany and the United Kingdom that the impact of divorce on pension entrance differs between countries, which she attributed to the country differences in terms of policies on pension sharing between spouses.

\section{Life histories and subjective processes surrounding retirement}

In the literature on life histories and retirement, there are only a handful of studies that simultaneously examine several aspects of the process of retirement (e.g., Han and Moen 1999, Damman et al. 2011, Moen et al. 2005). Moreover, the relationships between earlier life 
experiences and more subjective aspects of the retirement process - such as the way in which individuals experience their retirement - have only received limited attention thus far in quantitative studies. Some qualitative studies have suggested, however, that earlier life experiences might be important for understanding perceptions of retirement and adjustment. Patterns of discontinuity earlier in life, such as multiple job positions, have been suggested to limit perceived control over late-career work and retirement transitions (Fournier et al. 2011), but also might assist individuals in dealing with later-life challenges, such as the transition into retirement (Nuttman-Shwartz 2004, Price 2000). Moreover, the ease of adjustment to retirement may be dependent upon attachment to the work role over the life course (Barnes and Parry 2004). For example, Kloep and Hendry (2006) have concluded that "adjustment to retirement seemed relatively easy for those women who always had a second role as home-makers. They simply shifted from one possible self to another well-established one" (p.590). Even though these qualitative studies suggest that earlier life experiences are of importance for understanding subjective processes surrounding the act of retirement, insights into these relationships based on quantitative studies are still scarce. Existing studies suggest that both work career experiences (e.g., career path) and marital histories are associated with differences between retirees in terms of their retirement satisfaction (Price and Joo 2005, Quick and Moen 1998) and the extent to which they miss aspects of work after retirement (Damman et al. 2013b). For example, divorced retirees without a partner have been found to be more likely to miss the social dimensions of work (i.e., social contacts and social status) compared with continuously married retirees, and those who repartnered after divorce are more likely to miss financial resources (Damman et al. 2013b). 


\section{Conclusion and discussion}

The aging of populations in many developed countries has put the issue of retirement high on both scientific and policy agendas. To understand variation in retirement transitions, research has to a large extent focused on proximal precursors, that is, factors that are relatively close in time to retirement transitions. Recently, however, retirement research has broadened its view to more distal experiences earlier in life. The scientific literature on the role of life histories for understanding retirement transitions has grown rapidly during the last decade. The central purpose of this chapter was to provide an overview of the current state of scholarly discussions on life histories and retirement. Both theoretical approaches and empirical findings were described.

The review of the theoretical background of studies on life histories and retirement highlighted the life course perspective as the central guiding theoretical framework. Different mechanisms are theoretically distinguished to link earlier life experiences to retirement transitions. Earlier life experiences are assumed to affect retirement transitions via their consequences for the financial late-career opportunity structure, via the non-financial late-career opportunity structure, or via underlying orientations towards work and family. Consequently, opposing forces might be at work between specific earlier life experiences and retirement. Another complicating factor for formulating hypotheses on the relationships between earlier life experiences and retirement is that retirement transitions are not always fully the result of personal choice. Therefore, earlier life experiences can be expected to be stronger predictors of some aspects of the process of retirement (e.g., retirement intentions) than of other aspects (e.g., actual retirement behavior). 
The overview of empirical literature on life histories and retirement generally suggests that life histories are of importance for understanding retirement-related decisions and experiences. Various earlier life experiences in both the work and family life spheres have been shown to "set the stage" (Settersten 2003, p.29) for the way in which older individuals approach their later years. The empirical research on life histories and retirement is, however, still rather fragmented. The aspects of the retirement process receiving attention, types of earlier life experiences examined, ways of measuring life histories, sampling frames, country contexts, and birth cohorts all differ greatly between studies. This makes it hard to compare the findings and draw overarching conclusions regarding associations between specific earlier life experiences and retirement. There still remain a lot of puzzles to be solved and questions to be answered, to further improve our insights regarding the life course embeddedness of retirement.

\section{Future directions}

Retirement is increasingly conceptualized as a long-term and multidimensional process embedded within interdependent life trajectories in different life spheres. This conceptualization has implications for the focus, theoretical approach, and study design of future research on life histories and retirement.

Firstly, a central assumption of the life course perspective is that individual development is 'multispheral' (Settersten 2003), which implies that individual development takes place in multiple life spheres and that experiences in these different spheres are closely connected to each other. Further extending the types of earlier life experiences studied - and examining them simultaneously - might therefore improve our understanding of retirement and its life history predictors. Even though earlier life experiences in areas that are central to the lives of individuals 
(such as their work and family) are addressed in the existing literature, other potentially important areas of life such as education and training, involvement in unpaid work, leisure activities, health trajectories, and migration history are covered to a lesser extent. Moreover, the literature is largely focused on earlier life experiences of older individuals themselves. In line with the life course notion of 'linked lives', it can be expected that earlier life experiences of the spouse play a role as well. To study the role of the partner's life history researchers may consider adopting a 'multi-actor' research design, in which not only older workers but also their partners are asked about their experiences earlier in life.

Secondly, retirement is often conceptualized as being a long-term process consisting of several broad phases, such as preretirement planning, retirement decision-making, and postretirement adjustment (Wang and Shultz 2010). Most empirical studies on life histories and retirement focus on just one aspect of the retirement process, that is on actual retirement behavior. More subjective aspects of the retirement process that precede or follow upon this behavior have received only limited attention thus far, as well as the way in which individuals shape their lives in retirement. For instance, one specific aspect of this postretirement process that needs further study is the phenomenon of "bridge employment", which might either reflect a continuation of unstable employment trajectories or a major career shift (Henretta 2003). Given that the impact of earlier life experiences can be expected to vary across aspects of the retirement process, simultaneously examining various aspects of the retirement process might be informative. This would require a longitudinal research design, in which older workers are followed over time in their transitions from work into retirement.

Thirdly, paying more systematic attention to the mechanisms linking earlier life experiences to retirement transitions might be useful, because this will offer insights into the 
question why (or why not) earlier life experiences are related to retirement. Some studies have started to pay more attention to these linking mechanisms, for example by building statistical models in different steps and by testing the mediating role of the late-career opportunity structure. In a first step the effects of earlier life experiences are estimated without taking measures of the late-career opportunity structure into account. In a second step, measures of the late-career opportunity structure are included (e.g., Damman et al. 2011, Raymo et al. 2011). Both studies that take this approach conclude, however, that the life history effects cannot be fully explained by the temporally proximate correlates. These findings might - on the one hand reflect that the measures of the late-career opportunity structure do not fully capture all relevant aspects of the situation of older individuals. On the other hand, the findings might indicate that other mechanisms (e.g., orientations towards work and family) are of importance for explaining the research findings, for which the theory and data collected still need to be developed further.

Fourth, more attention is needed for the role of the country contexts in which studies on life histories and retirement are conducted and their implications for the study findings. Given that countries differ considerably in their pension systems, welfare arrangements, divorce laws, and family policies, we should be careful with generalizing results from one specific country to other countries (Wang 2012). Explicitly testing differences in terms of the effects of earlier life experiences on retirement transitions between countries that vary in terms of welfare state regimes (cf. Fasang 2008, who compares pathways to old age pension in Germany and the United Kingdom) may therefore be a fruitful direction for future research. This would need data in which comparable measures of life histories and retirement are available across countries. Initiatives like the SHARELIFE data, might offer opportunities in this respect (see, for example, Hank and Korbmacher 2013). 


\section{Implications}

Not only in the scientific literature, but also in the policy-oriented literature it has been assumed that earlier life experiences continue to affect the lives of individuals even in their later years. For example, it has been suggested that to encourage later retirement, policy interventions might already focus on workers at younger ages (OECD 2006). The existing research on life histories and retirement generally seems to support the underlying assumption that earlier life events in several life spheres are associated with retirement-related decisions and experiences. This suggests that public and organizational policies aiming at prolonged employment might benefit from viewing retirement as an integral part of the individual life course. It should be emphasized, however, that the current literature on life histories and retirement does not directly test the longterm implications of specific early or mid-career policy measures or practices, but rather focuses on general life events that are often beyond the control of the organization. Further research might therefore be needed in this respect.

A better understanding of how retirement transitions of current retirees are related to their experiences earlier in life might also nourish ideas or expectations about how changing life course experiences will shape the retirement transitions of future retirees. During the second half of the twentieth century individual life courses have become increasingly diverse. Both work careers and partner relationships seem to have become more versatile, and major responsibilities such as having children are increasingly postponed. Several of these increasingly common life experiences - such as job mobility and the experience of a divorce later in mid-life - have been found to be associated with continued labor force participation and later retirement. When linking the societal developments to these research findings and assuming that relationships 
between earlier life experiences and retirement are similar among younger cohorts, several changes in life courses can be expected to contribute to a future trend towards later retirement. It should be noted, however, that these expected changes in retirement transitions might intermingle with a trend towards later retirement prompted by recent changes in labor market and retirement policies.

Not only have individual life courses changed considerably and are becoming less standardized, but the societal context in which older individuals make their retirement decisions is also changing rapidly. In many developed societies this context is shifting from a focus on early retirement to a focus on continued labor participation, which is often accompanied by growing financial uncertainty and individual responsibility with regard to preparing and saving for retirement years. As a result of these developments, retirement transitions and experiences might become increasingly heterogeneous and complex. Moreover, these developments might impact the strength of the relationships between earlier life experiences and retirement, as well as the mechanisms linking the lived past to the present situation. Whether the associations between earlier life experiences and the different phases of the retirement process will be similar among cohorts approaching retirement in the future therefore remains an important question for future research. 


\section{References}

Barnes, H. and Parry, J. (2004) 'Renegotiating identity and relationships: Men and women's adjustment to retirement', Ageing \& Society, 24(2), 213-233.

Beehr, T. A. (1986) 'The process of retirement: A review and recommendations for future investigation', Personnel Psychology, 39(1), 31-55.

Beehr, T. A. and Bowling, N. A. (2012) 'Variations on a retirement theme: Conceptual and operational definitions of retirement' in Wang, M., ed. The Oxford handbook of retirement, Oxford: Oxford University Press, 42-55.

Blackwell, D. L., Hayward, M. D. and Crimmins, E. M. (2001) 'Does childhood health affect chronic morbidity in later life?', Social Science \& Medicine, 52(8), 1269-1284.

Blossfeld, H. P., Mills, M. and Bernardi, F. (2006) Globalization, uncertainty and men's careers. An international comparison, Cheltenham, UK: Edward Elgar Publishing.

Börsch-Supan, A., Brandt, M. and Schröder, M. (2013) 'SHARELIFE—One century of life histories in Europe', Advances in Life Course Research, 18(1), 1-4. 
Brown, T. H. and Warner, D. F. (2008) 'Divergent pathways? Racial/ethnic differences in older women's labor force withdrawal', Journal of Gerontology: Social Sciences, 63B(3), S122S134.

Choi, N. G. (2002) 'Self-defined retirement status and engagement in paid work among older working-age women: Comparison between childless women and mothers', Sociological Inquiry, 72(1), 43-71.

Chung, H.-Y. (2010) The effects of childbearing patterns on the timing of retirement, unpublished thesis University of Massachusetts Boston.

Damman, M., Henkens, K. and Kalmijn, M. (2011) 'The impact of midlife educational, work, health, and family experiences on men's early retirement', The Journals of Gerontology Series B: Psychological Sciences and Social Sciences, 66(5), 617-627.

Damman, M., Henkens, K. and Kalmijn, M. (2013a) 'Late-career work disengagement: The role of proximity to retirement and career experiences', Journals of Gerontology, Series B: Psychological Sciences and Social Sciences, 68(3), 455-463.

Damman, M., Henkens, K. and Kalmijn, M. (2013b) 'Missing work after retirement: The role of life histories in the retirement adjustment process', The Gerontologist, Advance Access published December 31, 2013. 
Damman, M., Henkens, K. and Kalmijn, M. (2014) Family histories and women's retirement: the role of childbearing and marital experiences, Tilburg: Network for Studies on Pensions, Aging and Retirement (NETSPAR)

Denton, F. T. and Spencer, B. G. (2009) 'What is retirement?: A review and assessment of alternative concepts and measures', Canadian Journal on Aging-Revue Canadienne Du Vieillissement, 28(1), 63-76.

Dykstra, P. A., Kraaykamp, G., Lippe, T. v. d. and Schippers, J. (2007) 'Perspectief op de levensloop [Perspective on the life course]' in Lippe, T. v. d., Dykstra, P. A., Kraaykamp, G. and Schippers, J., eds., De maakbaarheid van de levensloop, Assen: Koninklijke Van Gorcum BV, 1-8.

Ekerdt, D. J. (2010) 'Frontiers of Research on Work and Retirement', Journals of Gerontology Series B-Psychological Sciences and Social Sciences, 65(1), 69-80.

Ekerdt, D. J. and DeViney, S. (1993) 'Evidence for a preretirement process among older male workers', Journal of Gerontology: Social Sciences, 48B(2), S35-S43.

Elder, G. H. (1994) 'Time, human agency, and social change: Perspectives on the life course', Social Psychology Quarterly, 57(1), 4-15. 
Elder, G. H. and Johnson, M. K. (2003) 'The life course and aging. Challenges, lessons, and new directions' in Settersten, R. A., ed. Invitation to the life course. Towards new understandings of later life, New York: Baywood, 49-81.

Elder, G. H. and Pavalko, E. K. (1993) 'Work careers in men's later years: Transitions, trajectories, and historical change', Journal of Gerontology: Social Sciences, 48(4), S180S191.

Fasang, A. E. (2008) Family Biographies and Retirement Processes. A comparative analysis of West Germany and the United Kingdom, unpublished thesis Jacobs University Bremen.

Fasang, A. E., Aisenbrey, S. and Schömann, K. (2012) 'Women's retirement income in Germany and Britain', European Sociological Review, 29(5), 968-980.

Feldman, D. C. and Beehr, T. A. (2011) 'A three-phase model of retirement', American Psychologist, 66(3), 193-203.

Finch, N. (2014) 'Why are women more likely than men to extend paid work? The impact of work-family life history', European Journal of Ageing, 11, 31-39. 
Flippen, C. and Tienda, M. (2000) 'Pathways to retirement: Patterns of labor force participation and labor market exit among the pre-retirement population by race, Hispanic origin, and sex', Journals of Gerontology Series B-Psychological Sciences and Social Sciences, 55(1), S14-S27.

Fokkema, T. and Van Solinge, H. (2000) 'De invloed van de huwelijksgeschiedenis op het inkomen van ouderen [The influence of the marriage history on the income of the elderly]', Sociale Wetenschappen, 43(4), 19-40.

Fournier, G., Zimmermann, H. and Gauthier, C. (2011) 'Instable career paths among workers 45 and over: Insight gained from long-term career trajectories', Journal of Aging Studies, 25, 316-327.

Han, S. K. and Moen, P. (1999) 'Clocking out: Temporal patterning of retirement', American Journal of Sociology, 105(1), 191-236.

Hank, K. (2004) 'Effects of early life family events on women's late life labour market behaviour: An analysis of the relationship between childbearing and retirement in western Germany', European Sociological Review, 20(3), 189-198.

Hank, K. (2010) 'Childbearing history, later-life health, and mortality in Germany', Population Studies, 64(3), 275-291. 
Hank, K. and Korbmacher, J. M. (2013) 'Parenthood and retirement. Gender, cohort, and welfare regime differences', European Societies, 15(3), 446-461.

Hayward, M. D., Friedman, S. and Chen, H. (1998) 'Career trajectories and older men's retirement', Journal of Gerontology: Social Sciences, B53(2), S91-S103.

Hayward, M. D., Grady, W. R., Hardy, M. A. and Sommers, D. (1989) 'Occupational influence on retirement, disability and death', Demography, 26(3), 393-409.

Henkens, K. (1998) Older workers in transition. Studies on the early retirement decision in the Netherlands, unpublished thesis (Dissertation), Utrecht University.

Henretta, J. C. (2003) 'The life-course perspective on work and retirement' in Settersten, R. A., ed. Invitation to the life course. Towards new understandings of later life, New York: Baywood, 85-105.

Henretta, J. C., O'Rand, A. M. and Chan, C. G. (1993) 'Joint role investments and synchronization of retirement. A sequential approach to couples' retirement timing', Social Forces, 71(4), 981-1000. 
Hiekel, N. (2014) The different meanings of cohabitation across Europe. How cohabiters view their unions and differ in their plans and behaviors, Amsterdam: Amsterdam University Press.

Ho, J.-H. and Raymo, J. M. (2009) 'Expectations and realization of joint retirement among dualworker couples', Research on Aging, 31(2), 153-179.

Holden, K. C. and Kuo, H. H. D. (1996) 'Complex marital histories and economic well-being: The continuing legacy of divorce and widowhood as the HRS cohort approaches retirement', The Gerontologist, 36(3), 383-390.

Hyllegard, D. and Lavin, D. E. (1992) 'Higher education and challenging work: Open admissions and ethnic and gender differences in job complexity', Sociological Forum, 7(2), 239-260.

Jones, D. A. and McIntosh, B. R. (2010) 'Organizational and occupational commitment in relation to bridge employment and retirement intentions', Journal of Vocational Behavior, 77, 290-303.

Kloep, M. and Hendry, L. B. (2006) 'Pathways into retirement: Entry or exit?', Journal of Occupational and Organizational Psychology, 79, 569-593. 
Kovalenko, M. and Mortelmans, D. (2013) A comparative perspective on career mobility in Europe: career patterns and their effects on retirement timing, WSE-report ; 2013:10, Leuven: Steunpunt Werk en Sociale Economie.

Liefbroer, A. C. and Dykstra, P. A. (2000) Levenslopen in verandering: een studie naar ontwikkelingen in de levenslopen van Nederlanders geboren tussen 1900 en 1970 [Changing life courses: a study on the developments in life courses of Dutchmen born between 1900 and 1970], Voorstudies en Achtergronden V107, Den Haag, NL: Sdu uitgevers.

Lindenberg, S. (2006) 'Rational choice theory' in Beckert, J. and Zafirovski, M., eds., International Encyclopedia of Economic Sociology, New York: Routledge, 548-552.

Luijkx, R., Kalmijn, M. and Muffels, R. J. A. (2006) 'The impact of globalization on job and career mobility of Dutch men: Life-history data from the mid-1950s to the year 2000' in Blossfeld, H. P., Mills, M. and Bernardi, F., eds., Globalization, uncertainty and men's careers Cheltenham, UK: Edward Elgar Publishing, 117-144.

Mayer, K. U. (2009) 'New directions in life couse research', Annual Review of Sociology, 35, 413-433. 
Mills, M. and Blossfeld, H. P. (2006) 'Globalization, patchwork careers and the individualization of inequality? A 12-country comparison of men's mid-career job mobility' in Blossfeld, H. P., Mills, M. and Bernardi, F., eds., Globalization, uncertainty and men's careers. An international comparison, Cheltenham, UK: Edward Elgar Publishing, 457-482.

Mills, M., Johnston, A. D. and DiPrete, T. A. (2006) 'Globalization and men's job mobility in the United States' in Blossfeld, H. P., Mills, M. and Bernardi, F., eds., Globalization, uncertainty and men's careers, Cheltenham, UK: Edward Elgar Publishing, 328-361.

Moen, P., Sweet, S. and Swisher, R. (2005) 'Embedded career clocks: The case of retirement planning', Advances in Life Course Research, 9, 237-265.

Mutchler, J. E., Burr, J. A., Pienta, A. M. and Massagli, M. P. (1997) 'Pathways to labor force exit: Work transitions and work instability', Journal of Gerontology: Social Sciences, 52B(1), S4-S12.

Nuttman-Shwartz, O. (2004) 'Like a high wave: Adjustment to retirement', The Gerontologist, 44(2), 229-236.

O'Rand, A. M. (1996) 'The precious and the precocious: Understanding cumulative disadvantage and cumulative advantage over the life course', The Gerontologist, 36(2), 230-238. 
O'Rand, A. M. and Henretta, J. C. (1982) 'Delayed career entry, industrial pension structure, and early retirement in a cohort of unmarried women', American Sociological Review, 47, 363-365.

OECD (2002) 'Women at work: who are they and how are they faring?' in OECD employment outlook 2002, Paris: OECD, 63-125.

OECD (2006) Live longer, work longer. Ageing and employment policies., Paris: Organisation of Economic Co-operation and Development.

OECD (2014a) 'Incidence of FTPT employment - common definition', [online], available: http://stats.oecd.org [accessed November 26, 2014].

OECD (2014b) 'LFS by sex and age - indicators', [online], available: http://stats.oecd.org [accessed November 17, 2014].

OECD (2014c) 'OECD Family Database', [online], available: www.oecd.org/social/family/database.htm [accessed November 13, 2014]. 
Peters, A. and Liefbroer, A. C. (1997) 'Beyond marital status: Partner history and well-being in old age', Journal of Marriage and the Family, 59(3), 687-699.

Pienta, A. M. (1999) 'Early childbearing patterns and women's labor force behavior in later life', Journal of Women and Aging, 11(1), 69-84.

Pienta, A. M. (2003) 'Partners in marriage: An analysis of husbands' and wives' retirement behavior', The Journal of Applied Gerontology, 22(3), 340-358.

Pienta, A. M., Burr, J. A. and Mutchler, J. E. (1994) 'Women's labor force participation in later life: The effects of early work and family experiences', Journal of Gerontology: Social Sciences, 49B(5), S231-S239.

Price, C. A. (2000) 'Women and retirement: Relinquishing professional identity', Journal of Aging Studies, 14(1), 81-101.

Price, C. A. and Joo, E. (2005) 'Exploring the relationship between marital status and women's retirement satisfaction', The International Journal of Aging and Human Development, 61(1), 37-55. 
Price, D. and Ginn, J. (2003) 'Sharing the crust? Gender, partnership status and inequalities in pension accumulation' in Arber, S., Davidson, K. and Ginn, J., eds., Gender and ageing. Changing roles and relationships, Buckingham: Open University Press, 127-147.

Quick, H. E. and Moen, P. (1998) 'Gender, employment, and retirement quality: A life course approach to the differential experiences of men and women', Journal of Occupational Health Psychology, 3(1), 44-64.

Raymo, J. M., Warren, J. R., Sweeney, M. M., Hauser, R. M. and Ho, J.-H. (2009) Mid-life work experiences and first retirement, Madison: University of Wisconsin-Madison, Center for Demography and Ecology.

Raymo, J. M., Warren, J. R., Sweeney, M. M., Hauser, R. M. and Ho, J.-H. (2010) 'Later-life employment preferences and outcomes: The role of midlife work experiences', Research on Aging, 32(4), 419-466.

Raymo, J. M., Warren, J. R., Sweeney, M. M., Hauser, R. M. and Ho, J.-H. (2011) 'Precarious employment, bad jobs, labor unions, and early retirement', The Journals of Gerontology Series B: Psychological Sciences and Social Sciences, 66B(2), 249-259.

Schalk, R., Van Veldhoven, M. J. P. M., De Lange, A. H., De Witte, H., Kraus, K., StamovRossnagel, C., Tordera, N., Van der Heijden, B., Zappala, S., Bal, M., Bertrand, F., 
Claes, R., Crego, A., Dorenbosch, L. W., De Jonge, J., Desmette, D., Gellert, F. J., Hansez, I., Iller, C., Kooij, D., Kuipers, B., Linkola, P., Van den Broeck, A., Van der Schoot, E. and Zacher, H. (2010) 'Moving European research on work and ageing forward: Overview and agenda', European Journal Of Work And Organizational Psychology, 19(1), 76-101.

Settersten, R. A. (2003) 'Propositions and controversies in life-course scholarship' in Settersten, R. A., ed. Invitation to the life course. Towards new understandings of later life, New York: Baywood, 15-48.

Shultz, K. S. and Wang, M. (2011) 'Psychological perspectives on the changing nature of retirement', American Psychologist, 66(3), 170-179.

Singh, G. and Verma, A. (2003) 'Work history and later life labor force participation: Evidence from a large telecommunications firm', Industrial and Labor Relations Review, 56(4), $669-715$.

Szinovacz, M. E. (1989) 'Decision-making on retirement timing' in Brinberg, J. and Jaccard, J., eds., Dyadic decision making, New York: Springer, 286-310. 
Szinovacz, M. E. (2003) 'Contexts and pathways: Retirement as institution, process, and experience' in Adams, G. A. and Beehr, T. A., eds., Retirement. Reasons, Processes and Results, New York: Springer, 6-52.

Szinovacz, M. E. and Davey, A. (2005) 'Predictors of perceptions of involuntary retirement', The Gerontologist, 45(1), 36-47.

Szinovacz, M. E. and DeViney, S. (1999) 'The retiree identity: Gender and race differences', Journal of Gerontology: Social Sciences, 54B(4), S207-S218.

Szinovacz, M. E. and DeViney, S. (2000) 'Marital characteristics and retirement decisions', Research on Aging, 22(5), 470-498.

Van Solinge, H. (2012) 'Adjustment to retirement' in Wang, M., ed. The Oxford handbook of retirement, New York: Oxford University Press, 311-324.

Van Solinge, H. and Henkens, K. (2005) 'Couples' adjustment to retirement: A multi-actor panel study', Journals of Gerontology Series B-Psychological Sciences and Social Sciences, 60(1), S11-S20. 
Van Solinge, H. and Henkens, K. (2007) 'Involuntary retirement: The role of restrictive circumstances, timing, and social embeddedness', Journals of Gerontology Series BPsychological Sciences and Social Sciences, 62(5), S295-S303.

Van Solinge, H. and Henkens, K. (2014) 'Work-related factors as predictors in the retirement decision-making process of older workers in the Netherlands', Ageing and society, 34(9), $1551-1574$.

Wahrendorf, M., Blane, D., Bartley, M., Dragano, N. and Siegrist, J. (2013) 'Working conditions in mid-life and mental health in older ages', Advances in Life Course Research, 18(1), $16-25$.

Wang, M. (2007) 'Profiling retirees in the retirement transition and adjustment process. Examining the longitudinal change patterns of retiree's psychological well-being', Journal of Applied Psychology, 92(2), 455-474.

Wang, M. (2012) 'Retirement research: Concluding observations and strategies to move forward' in Wang, M., ed. The Oxford handbook of retirement, Oxford: Oxford University Press, 603-615.

Wang, M., Henkens, K. and van Solinge, H. (2011) 'Retirement adjustment. A review of theoretical and empirical advancements', American Psychologist, 66(3), 204-213. 
Wang, M. and Shultz, K. S. (2010) 'Employee retirement: A review and recommendations for future investigation', Journal of Management, 36(1), 172-206.

Wheaton, F. and Crimmins, E. M. (2012) 'The demography of aging and retirement' in Wang, M., ed. The Oxford handbook of retirement, Oxford: Oxford University Press, 22-41.

Wilmoth, J. and Koso, G. (2002) 'Does marital history matter? Marital status and wealth outcomes among preretirement adults', Journal of Marriage and Family, 64, 254-268.

Wong, J. D. and Hardy, M. A. (2009) 'Women's retirement expectations: How stable are they?', The Journals of Gerontology Series B: Psychological Sciences and Social Sciences, 64B(1), 77-86.

Yabiku, S. T. (2000) 'Family history and pensions: The relationships between marriage, divorce, children, and private pension coverage', Journal of Aging Studies, 14(3), 293-312. 
Figure 1 Labor force participation rates in 2013 of individuals age 15-64 years in OECD countries, by gender

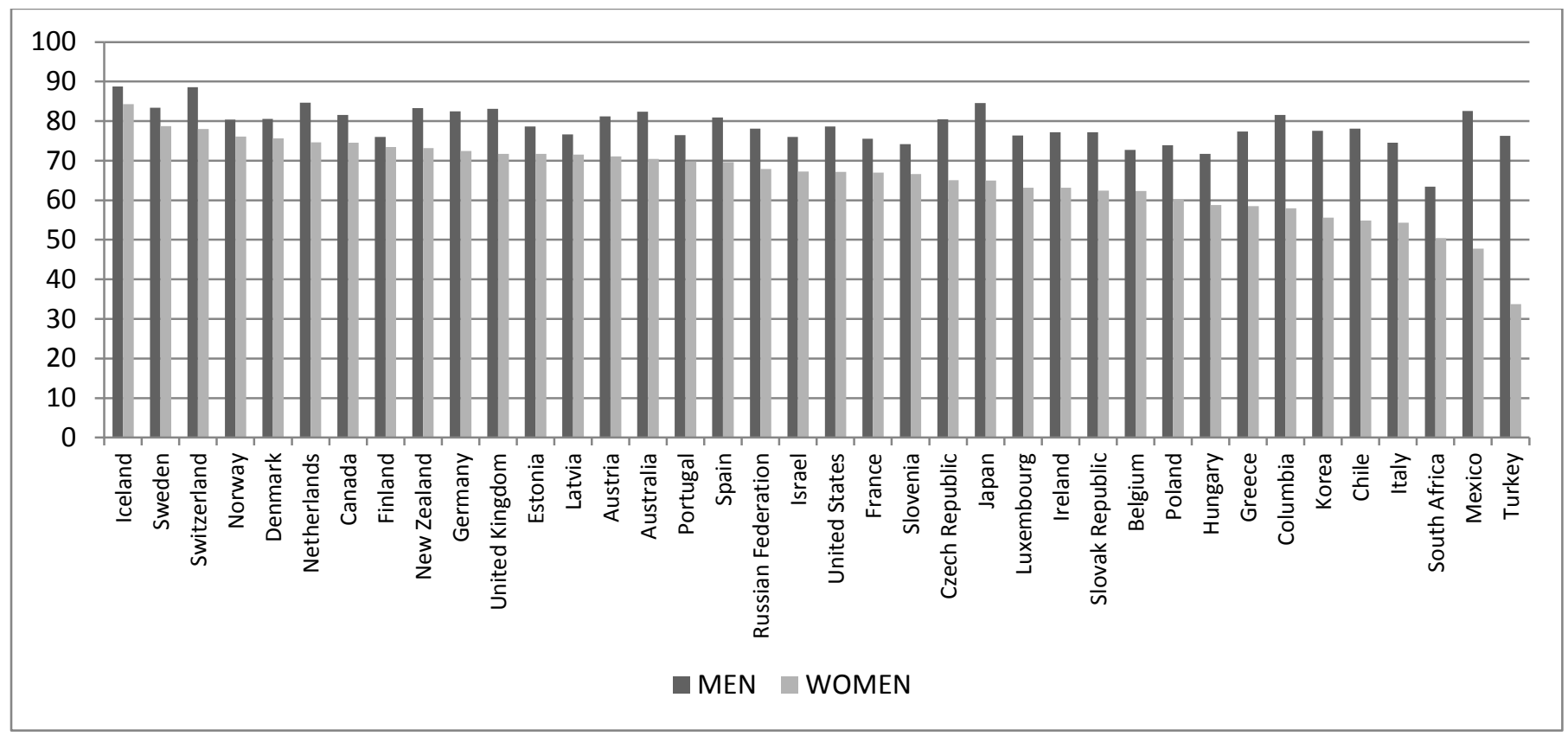

Source: OECD Labor Force Statistics (OECD 2014b) 
Figure 2 Completed fertility rates ${ }^{1}$, cohorts of women born in 1950 and 1965

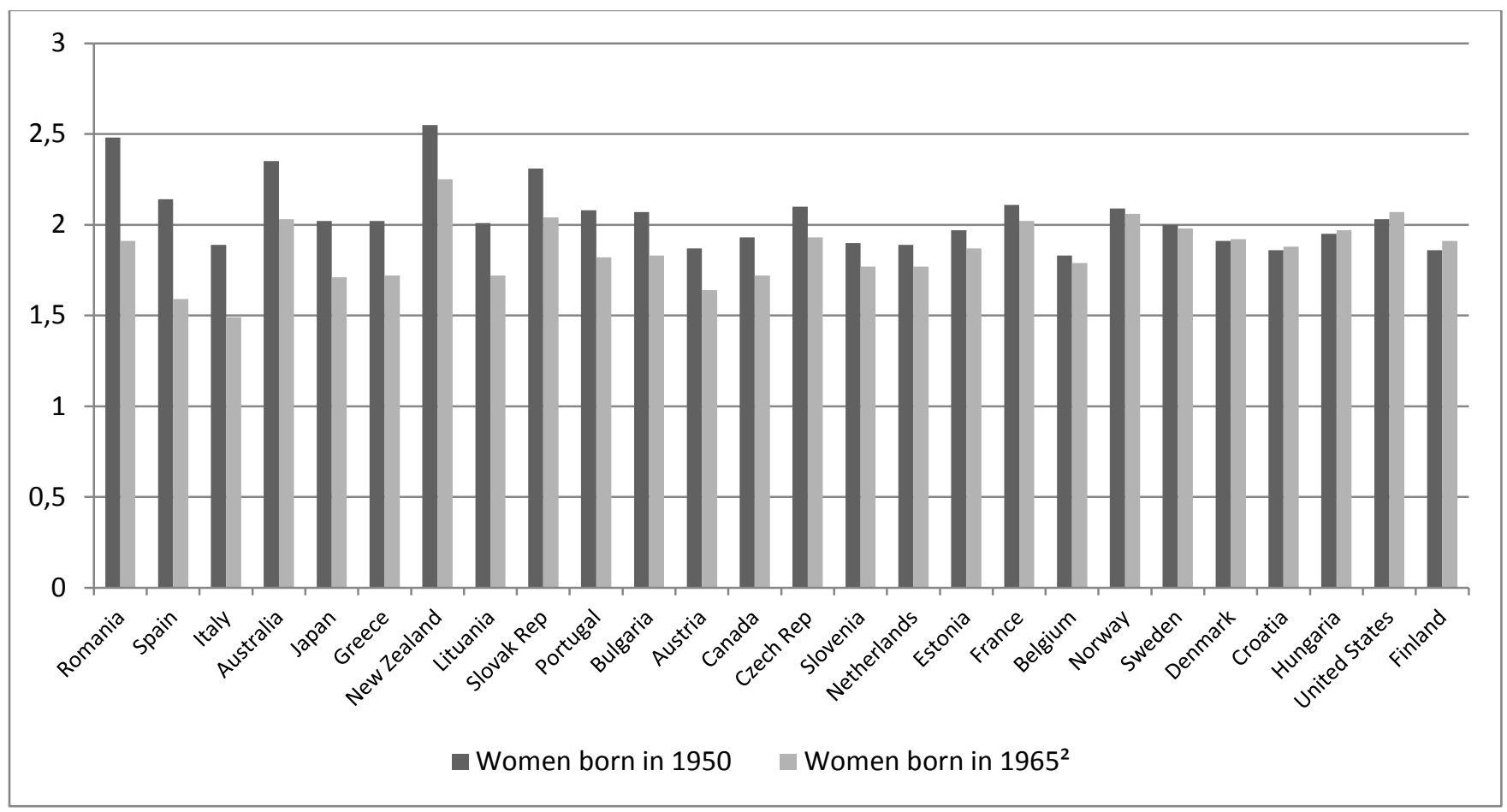

${ }^{1}$ Defined as the number of children actually born per woman for a given cohort of women by the end of their childbearing years. ${ }^{2}$ Women born in 1962 in Japan and 1964 in France.

Source: OECD Family Database (OECD 2014c) 
Figure 3 Crude divorce rates ${ }^{1}$ in selected OECD countries in 1970 and 2008

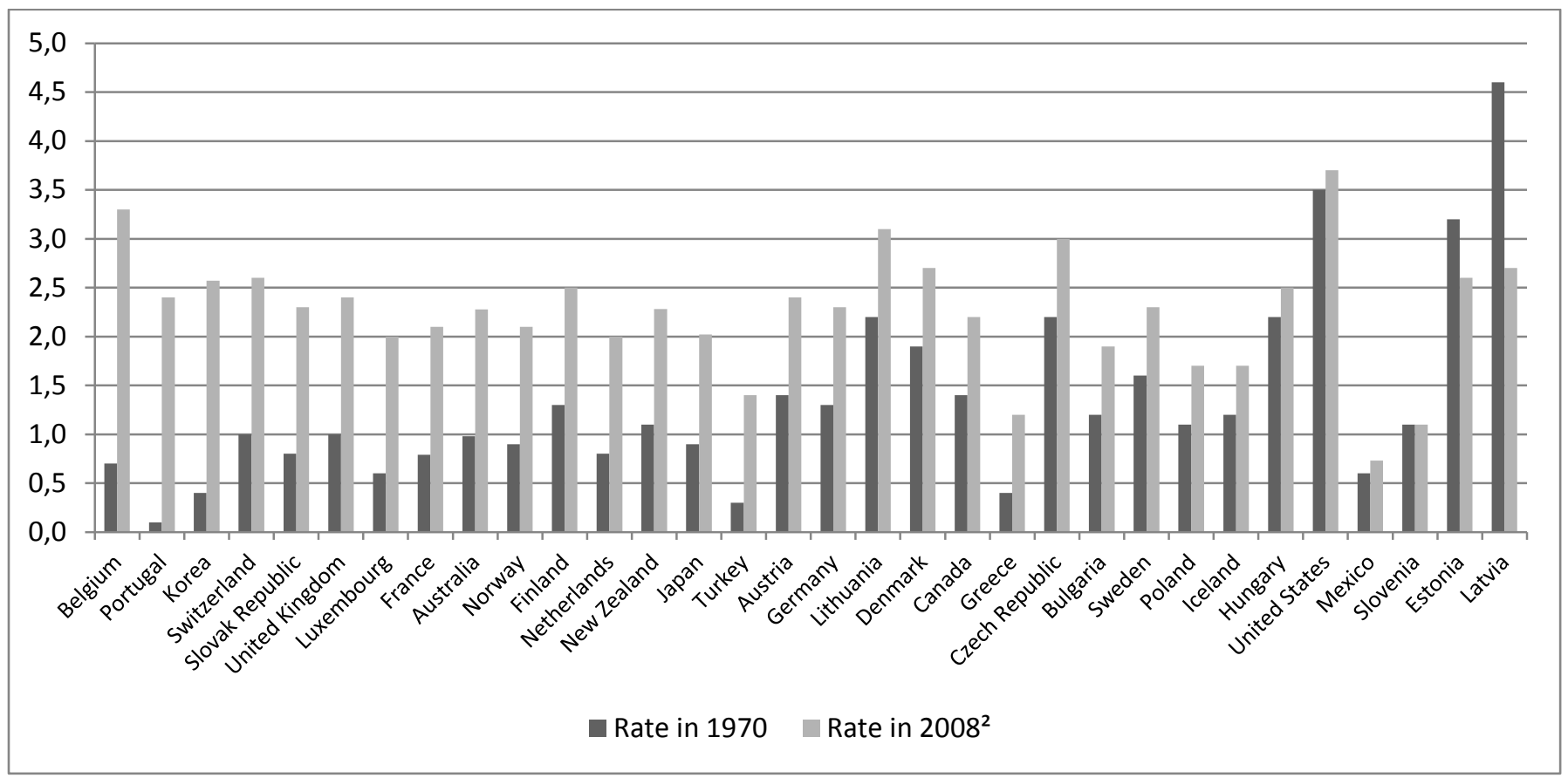

${ }^{1}$ Defined as the ratio of the number of marriages that are dissolved in a given year to the average population in that year, per 1000 inhabitants. ${ }^{2}$ Data refer to 2007 for the United Kingdom, Australia, Canada, Japan, Greece, and Mexico; 2006 for the Unites States, and France.

Source: OECD Family Database (OECD 2014c) 
Figure 4 Theoretical mechanisms linking earlier life experiences to retirement transitions

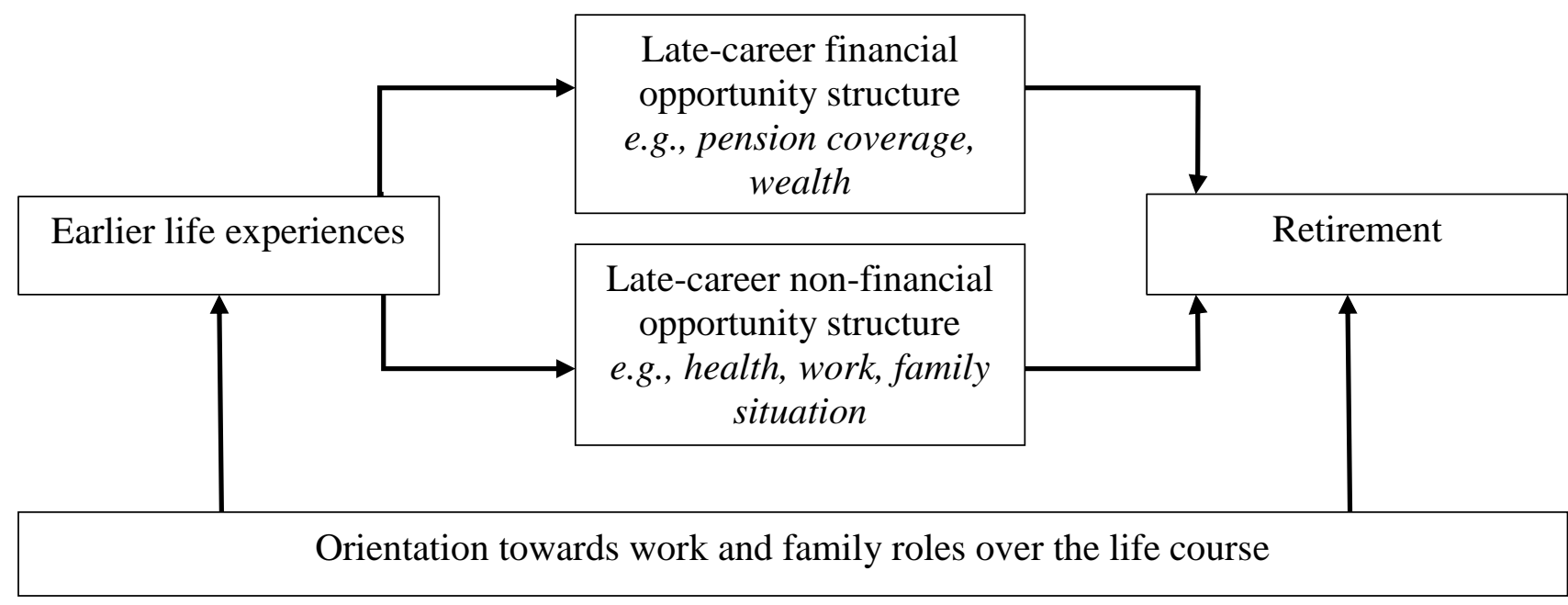


Even though "the consensus is that retirement is not a single event but rather a process that older individuals go through over a period of years" (Shultz and Wang 2011, p.170), what is actually meant by the term 'process' varies considerably between studies and scientific disciplines. The term has been used to indicate that retirement consists of several broad phases (e.g., preretirement planning, retirement decision-making, postretirement adjustment), but also to refer to more specific behavioral or attitudinal dynamics within or across these phases.

- The term 'retirement process' has been used to refer to the different phases individuals are assumed to go through when making the transition from work into retirement. From a "temporal perspective" (Shultz and Wang 2011, p.172) the retirement process is generally described as consisting of three main phases: preretirement preparation and planning for retirement, the retirement decision making process, and postretirement adjustment to the changed life circumstances in retirement (Wang and Shultz 2010, Shultz and Wang 2011).

- The terminology 'process of retirement' has been used to refer to the retirement decision making process, which might take place over a longer period of time. Beehr (1986) describes that "employees prefer to and then decide to retire before they actually do it, and this may take some time" (p.46), which implies that retirement preferences are followed by retirement intentions, and consequently by the act of retirement in the process of retirement. Szinovacz (1989) points at processes of negotiation and renegotiation between spouses before a retirement decision is reached.

- The term 'retirement planning process' has been used to refer to changes in retirement expectations over time (Wong and Hardy 2009), the term 'preretirement process' refers to changing attitudes when getting closer to retirement (Ekerdt and DeViney 1993, Damman et al. 2013a), and the term 'adjustment process' is often used to refer to changing attitudes after retirement (Wang 2007).

- The notion of retirement as a process has also been applied to indicate variation in employment pathways (i.e., sequences of states) during late careers. It refers, for example, to the notion that retirement is not necessarily an absorbing state, given that retirees can re-enter employment via bridge jobs and can have "blurred" exit pathways (Mutchler et al. 1997). 